\title{
MANAJEMEN PELAYANAN GIZI BURUK BERBASIS TEKNOLOGI DI KECAMATAN SUGIH WARAS KABUPATEN BOJONEGORO
}

\section{TECHNOLOGY BASED MALNUTRITION SERVICE MANAGEMENT IN SUGIH WARAS BOJONEGORO}

\author{
Falih Suaedi $^{1}$, Putu Aditya Ferdian Ariawantara ${ }^{2}$ \\ 1,2 Fakultas Ilmu Sosial dan Ilmu Politik Universitas Airlangga \\ e-mail: suaedifalih@yahoo.com ${ }^{1}$,putu.aditya.ferdian.ariawantara@ fisip.unair.ac.id ${ }^{2}$
}

\begin{abstract}
Half of all child deaths worldwide result from malnutrition (malnutrition). East Java Province provides the largest contribution from malnutrition in Indonesia and Sugih Waras District, Bojonegoro Regency, is one of the biggest contributors to malnutrition cases. Problems at the lower level often occur because there are still many posyandu that record data manually by writing it in the posyandu administration book or Kartu Menuju Sehat (KMS), which results in speed of decision making. This community service is about technology-based malnutrition service management including the creation of software (application), counseling, and demonstrations of how to use applications. The purpose of this community service activity is to provide practical knowledge to posyandu health cadres by means of counseling and villages in Sugih Waras Subdistrict, Bojonegoro Regency regarding the importance of posyandu management based on prevention technology that can reduce the number of malnutrition in Sugih Waras District, Bojonegoro Regency. The results of the pre-test and post-test on the capacity of the cadres showed an average increase of 65 percent. With this activity it helps posyandu cadres in providing fast and responsive health services and produces real time data.
\end{abstract}

Keywords: Cadres, Malnutrition, Posyandu

\section{abstrak}

Setengah dari kematian anak-anak di seluruh dunia akibat dari adanya kekurangan nutrisi (malnutrition). Provinsi Jawa Timur memberikan kontribusi terbesar malnutrition di Indonesia dan Kecamatan Sugih Waras Kabupaten Bojonegoro menjadi salah satu daerah terbesar penyumbang kasus malnutrition. Problematika pada level bawah sering terjadi karena masih banyak posyandu yang melakukan pencatatan data secara manual dengan ditulis di buku administrasi posyandu atau Kartu Menuju Sehat (KMS), yang berakibat pada kecepatan pengambilan keputusan. Kegiatan pengabdian masyarakat ini tentang manajemen pelayanan kesehatan berbasis teknologi meliputi pembuatan software (aplikasi), penyuluhan, dan demonstrasi penggunaan aplikasi. Tujuan kegiatan pengabdian masyarakat ini adalah untuk memberikan pengetahuan praktis kepada para kader-kader kesehatan posyandu dengan cara penyuluhan dan demonstrasi di Kecamatan Sugih Waras Kabupaten Bojonegoro mengenai pentingnya manajemen posyandu berbasis teknologi sebagai upaya preventif yang dapat menekan angka malnutrition di Kecamatan Sugih Waras Kabupaten Bojonegoro. Hasil pre-test dan post-test terhadap kapasitas para kader menunjukkan peningkatan rata-rata sebesar 65 persen. Dengan kegiatan ini dapat membantu para kader posyandu dalam memberikan pelayanan kesehatan yang cepat dan responsif serta menghasilkan data bersifat real time.

Kata Kunci: Kader, Malnutrition, Posyandu

10.20473/jlm.v5i1.2021.42-48

\section{(i) (2)}

Open acces under CC BY-SA license

Creative Commons Attribution-ShareAlike 4.0 International License 


\section{PENDAHULUAN}

Setengah dari kematian anak-anak di seluruh dunia sebagai akibat dari adanya gizi buruk atau kekurangan nutrisi (malnutrition) (Unicef, 2017). Penyebab terjadinya gizi buruk berasal dari masa kehamilan hingga dua tahun pertama kehidupan seorang anak. Riset Unicef menemukan bahwa 30 persen ibu kekurangan gizi pada masa kehamilan menyebabkan 41 juta bayi dan bayi baru lahir mengalami gizi buruk (Unicef, 2017). WHO menyebutkan bahwa penyebab gizi buruk adalah kekurangan nutrisi, infeksi yang terjadi berulang-ulang, dan stimulasi psikososial yang tidak memadai (WHO, 2013). WHO (2013) menyebutkan penderita gizi buruk rata-rata memiliki tubuh kerdil dengan kemampuan kognisi dan kinerja yang buruk. Sebagai dampak jangka panjang anak penderita gizi buruk memiliki peluang yang minimum dalam mamperoleh pendidikan dan pekerjaan yang layak. Sedangkan menurut Unicef (2017), gizi buruk kronis membunuh peluang dalam hidup untuk anak dan membunuh peluang bagi pembangunan suatu bangsa. Permasalahan gizi buruk juga dapat menambah biaya pengeluaran negara hingga 3 persen dari PDB (Unicef, 2017). Jika PDB Indonesia mencapai Rp 12.406,8 triliun maka kasus gizi buruk berpotensi memangkas Rp 372 triliun.

Indonesia termasuk dalam lima besar negara di dunia dengan jumlah anak yang mengalami keterhambatan tumbuh kembang, sekitar 29,6 persen juta anak di bawah 5 tahun mengalami malnutrition (Unicef, 2017). Pemerintah Indonesia telah melakukan upaya untuk mengatasi problematika malnutrition dengan program prioritas penanganan pada 50 kabupaten/kota dengan kasus terbesar (Tim Nasional Percepatan Penanggulangan Kemiskinan, 2017). Namun persentase malnutrition di Indonesia masih memprihatinkan. Komitmen dalam upaya penanganan malnutrition masih minim dan pengembangan kapasitas masyarakat pinggiran kurang memadai. Ditambah adanya Pandemi Covid-19 telah merubah cara dan perilaku kita menjalani kehidupan seharihari, termasuk di sektor pelayanan kesehatan. Berbagai studi menyatakan bahwa kondisi pandemi memiliki pengaruh dominan dalam menentukan perilaku masyarakat terhadap pelayanan kesehatan. Kita dapat mengambil pelajaran dari penurunan kunjungan sebesar 50 persen dan 32 persen terhadap pelayanan antenatal dan persalinan saat terjadi wabah Ebola di Liberia (McGovern dkk, 2017) dan adanya indikasi keengganan masyarakat untuk mengimunisasi dan menimbang balita di berbagai fasilitas kesehatan saat terjadi wabah Ebola di sejumlah Negara Afrika, yang mana tren tersebut terus berlanjut setelah wabah berakhir (Elston, 2016). Apabila tidak ditangani secara cepat dan tepat maka dampak pandemi ini dapat menyebabkan generation lost di masa depan.

Provinsi Jawa Timur memberikan kontribusi jumlah malnutrition terbesar di Indonesia dan Kabupaten Bojonegoro dengan 5.868 kasus atau 7,45 persen pada tahun 2019 (Dinas Kesehatan Provinsi Jawa Timur, 2019). Masih banyaknya kasus diasumsikan karena terlambat dalam melakukan penanganan dari berbagai pihak, terutama di street level. Salah satu hal yang menjadi masalah yaitu masih banyak Posyandu yang melakukan pencatatan data manual dengan ditulis di buku administrasi Posyandu atau Kartu Menuju Sehat (KMS). Sehingga proses penyampaian data pada kelompok pengambil keputusan membutuhkan waktu. Ditambah lagi proses pemeriksaan dengan data laporan menggunakan kertas memakan waktu yang sangat lama. Hal inilah yang mengakibatkan keterlambatan pengambilan keputusan yang menjadi penyebab utama keterlambatan penanganan kasus stunting. 
Disrupsi teknologi membuat manajemen pemerintahan baik pusat maupun daerah telah menerapkan digitaalisasi pada pelayanan mereka, terutama saat dunia memasuki masa Pandemi Covid-19 merupakan momen yang tepat untuk memaksimalkan digitalisasi. Penerapan pelayanan kesehatan digital pada Posyandu akan mempermudah pencatatan sehingga data lebih mudah diakses dan dipantau secara real time oleh para pengambil keputusan. Keakuratan dan keaktualan data menjadi sisi positif bagi para pengambil keputusan dan pembuat kebijakan agar manfaat kebijakan dapat diterima oleh penerima manfaat (beneficiaries) dengan tepat waktu dan sesuai dengan kebutuhan masyarakat. Inovasi dalam kegiatan ini adalah penerapan teknologi informasi dan komunikasi ke dalam pelayanan masyarakat sehingga diharapkan dapat mempercepat respon terhadap balita yang terindikasi malnutrition. Upaya preventif mengharapkan dapat menekan angka malnutrition di Kabupaten Bojonegoro sehingga kedepannya dapat menjadi daerah percontohan penanganan malnutrition berbasis teknologi.

\section{METODE PENGABDIAN MASYARAKAT}

Pengabdian masyarakat ini dilaksanakan berdasarkan analisis hasil penelitian dan diskusi dengan warga masyarakat yang tinggal di Desa Genjor Kecamatan Sugih Waras Kabupaten Bojonegoro Jawa Timur. Permasalahan yang terjadi yaitu manajemen penanganan malnutrition. Solusi yang ditawarkan melalui program pengabdian masyarakat dari Lembaga Penelitian dan Pengabdian Kepada Masyarakat (LPPM) dan Fakultas Ilmu Sosial dan Ilmu Politik Universitas Airlangga yaitu manajemen pelayanan publik berbasis teknologi meliputi pembuatan software (aplikasi), penyuluhan, dan demonstrasi penggunaan aplikasi.

Kegiatan pengabdian masyarakat ini dilaksanakan dalam beberapa tahap yaitu persiapan, pelaksanaan, dan evalusasi. Tahap persiapan dilakukan dengan penyuluhan tentang rencana pengabdian masyarakat kepada kader-kader posyandu, puskesmas dan aparatur desa dengan rincian kegiatan yaitu melakukan observasi terhadap sistem posyandu yang sudah berjalan dan dokumen-dokumen pencatatan administrasi yang ada (kondisi existing), menganalisa kebutuhan sistem informasi yaitu kebutuhan perangkat lunak (software), perangkat keras (hardware), dan pengguna sistem (brainware), serta melakukan pengembangan aplikasi Teknologi Tepat Guna (TTG) untuk meningkatkan kualitas pelayanan posyandu.

Tahap pelaksanaan dengan rincian kegiatan yaitu melakukan desain sistem informasi dengan Data Flow Diagram (DFD), menerapkan desain sistem informasi ke dalam bentuk sebuah aplikasi, penyuluhan dan demonstrasi kepada kader-kader posyandu mengenai prototype aplikasi pelayanan posyandu, penerapan aplikasi posyandu dalam kegiatan pelayanan kesehatan di Desa Genjor, Kabupaten Bojonegoro. 


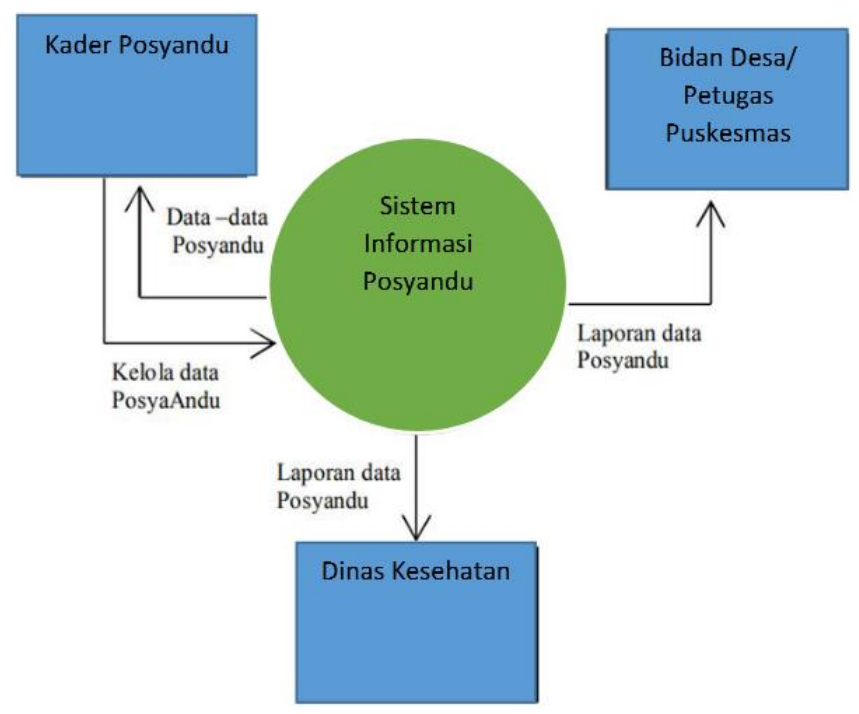

Gambar 1. Proses penerapan KMS berbasis digital

Tahap evaluasi dengan rincian kegiatan yaitu mereview hasil implementasi sistem informasi berbasis teknologi melalui pre-test yang dilakukan sebelum kegiatan dan post-test yang dilakukan setelah kegiatan berlangsung terhadap kader-kader posyandu dan mengumpulkan masukan dari berbagai pihak. Evalusasi dilakukan untuk mengetahui respon peserta dan mitra terhadap pelaksanaan kegiatan. Evaluasi dilakukan terhadap tingkat pemahaman dan partisipasi.

\section{HASIL DAN PEMBAHASAN}

Pengabdian masyarakat untuk meningkatkan manajemen penanganan malnutrition sebagai upaya preventif menekan angka malnutrition telah dilakukan oleh Tim Pengabdian Masyarakat di Kecamatan Sugih Waras Kabupaten Bojonegoro. Kegiatan diikuti oleh kader-kader Posyandu Kecamatan Sugih Waras. Kegiatan ini dilakukan pada tanggal 7-8 Oktober 2020 berupa penyuluhan dan demonstrasi.

Kegiatan penyuluhan dilakukan dengan menggunakan metode pemaparan secara visualisasi dengan menggunakan LCD. Sebelum melakukan penyuluhan, dilakukan pretest untuk mengetahui kapasitas kader-kader Posyandu Kecamatan Sugih Waras Kabupaten Bojonegoro. Penyuluhan ini dilakukan untuk mengatasi permasalahan pada masyarakat setempat yaitu perlu adanya sistem pelayanan berbasis digital untuk menghasilkan data real time sehingga proses penanganan menjadi lebih cepat dan responsif. Sedangkan kegiatan demonstrasi dilakukan dengan metode praktik secara langsung dengan menggunakan aplikasi yang dapat di download. Kegiatan demonstrasi bertujuan untuk memberikan arahan kepada para kader tentang cara penggunaan aplikasi posyandu berbasis android. 


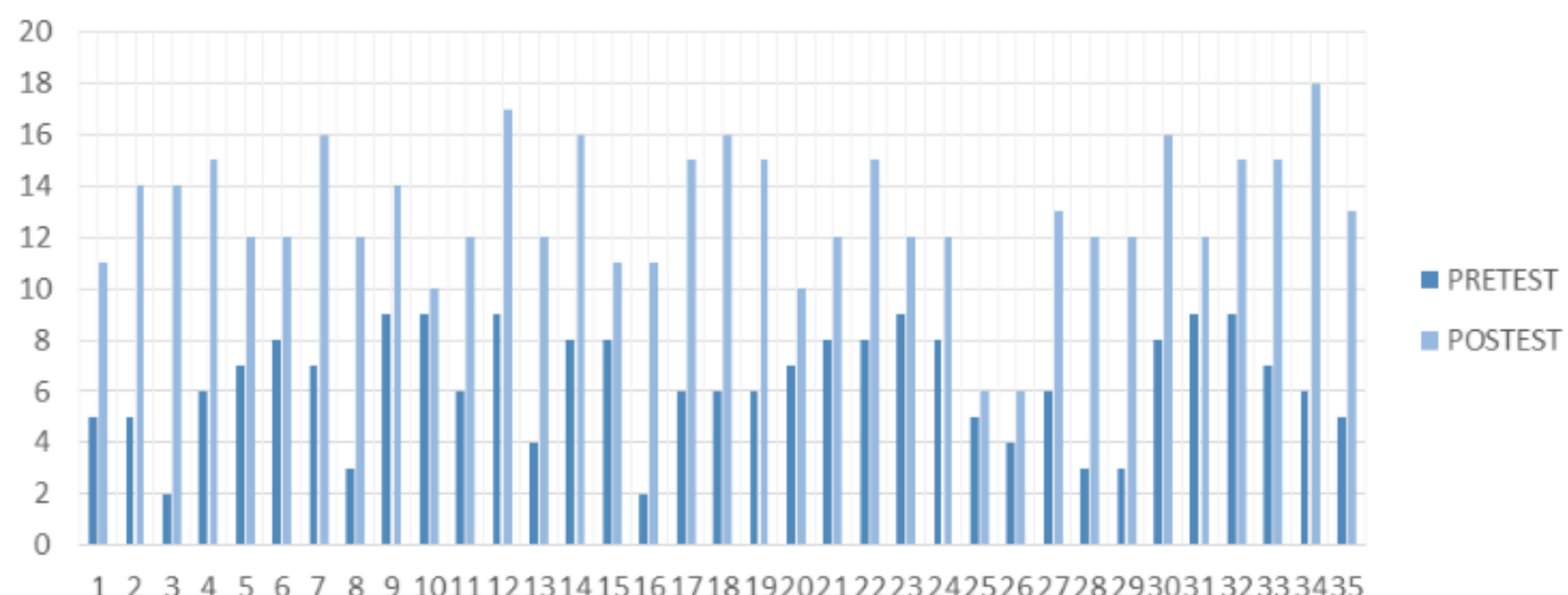

Tabel 1. Distribusi Peningkatan Kapasitas Kader Posyandu Kecamatan Sugih Waras Kabupaten Bojonegoro Sebelum dan Sesudah Kegiatan

Berdasarkan hasil evaluasi pres-test dan post-test yang telah dilakukan sebelum dan sesudah pelaksanaan penyuluhan dan demonstrasi mendapati bahwa kader-kader Posyandu di Kecamatan Sugih Waras Kabupaten Bojonegoro mengalami peningkatan kapasitas mengenai pemahaman manajemen posyandu berbasis digital. Pemberian penyuluhan dan demonstrasi dapat meningkatkan kapasitas peserta sehingga para kader posyandu mampu memahami dan menyerap serta memiliki pengetahuan terkait pentingnya teknologi informasi dalam mendukung pelayanan kesehatan dan bagaimana cara menggunakan aplikasi dalam pelayanan posyandu. Hal ini dibuktikan dengan hasil nilai pre-test (sebelum kegiatan) lebih tinggi dibandingkan nilai post-test (sesudah kegiatan). Dari 35 orang kader, semuanya memiliki nilai yang menunjukkan peningkatan yang signifikan dengan rata-rata 65 persen. Hal ini mengindikasikan bahwa hasil dari kegiatan pengabdian masyarakat tentang manajamen pelayanan publik berbasis teknologi di Kecamatan Sugih Waras Kabupaten Bojonegoro dapat dikatakan berhasil.

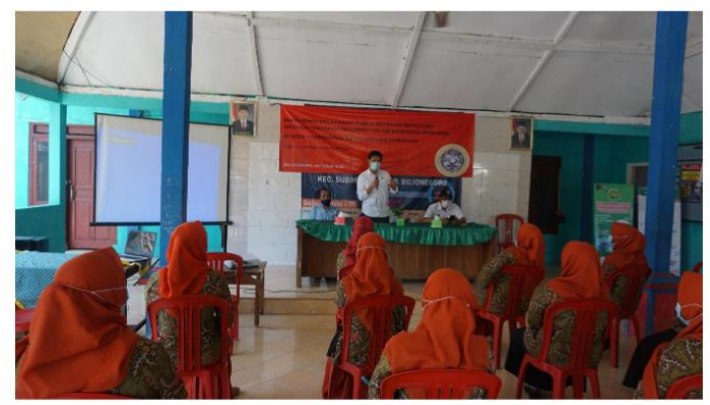

Gambar 2. Penyuluhan Mengenai Manajemen Pelayanan Kesehatan

Pelaksanaan kegiatan pengabdian masyarakat di Kecamatan Sugih Waras Kabupaten Bojonegoro ini berjalan dengan baik dan lancar. Pengabdian ini ditujukan kepada kaderkader Posyandu di Kecamatan Sugih Waras Kabupaten Bojonegoro dengan metode penyuluhan yaitu pemaparan materi yang dilakukan oleh para narasumber dan demonstrasi yaitu praktik langsung penggunaan aplikasi pelayanan posyandu. Pengabdian masyarakat ini diharapkan mampu menambah kapasitas kader-kader kesehatan posyandu dalam manajemen pelayanan berbasis teknologi yang mana 
menghasilkan data real time sehingga proses penanganan menjadi lebih cepat dan responsif.

Dalam proses penyuluhan berjalan seperti yang diharapkan yang dibuktikan dengan respon para kader-kader posyandu dalam menjawab pertanyaan yang diajukan dengan baik dan benar. Para kader juga memperhatikan proses demonstrasi penggunaan aplikasi pelayanan posyandu yang dilakukan pada kegiatan ini berjalan dengan baik yang didukung dengan praktik secara langsung dimana para kader juga dapat mempratikkannya.

Berdasarkan hasil evaluasi pelaksanaan kegiatan terdapat faktor pendukung dan penghambat dari kegiatan ini sehingga dapat berjalan dengan baik dan lancar. Faktor pendukung yaitu adanya dukungan dari berbagai pihak dari pemerintah desa, puskesmas, dinas kesehatan kabupaten, dan mitra yang terkait. Sedangkan faktor penghambat yaitu kegiatan ini dilaksanakan dalam kondisi Pandemi Covid-19 sehingga adanya keterbatasan tempat dan peserta dalam kegiatan.

Berdasarkan hasil evaluasi pelaksanaan kegiatan terdapat beberapa masukkan dari kegiatan ini untuk berjalan dengan lebih baik kedepannya. Masukkan dapat diidentifikasikan berdasarkan masukkan teratas yang sering diberikan yaitu perlu diintegrasikan aplikasi pelayanan posyandu dengan sistem informasi yang dimiliki oleh Dinas Kesehatan, tujuannya adalah agar terciptanya sebuah database baru yang terpadu, selain itu juga perlu dibentuk sistem informasi pelayanan posyandu berupa website yang terpadu dengan yang dimiliki oleh desa. Kegiatan ini juga perlu untuk dilanjutkan kepada tingkat yang lebih luas.

\section{PENUTUP}

\section{Simpulan}

Kegiatan pengabdian masyarakat ini memberikan pengetahuan praktis kepada para kader-kader kesehatan posyandu dengan cara penyuluhan dan demonstrasi di Kecamatan Sugih Waras Kabupaten Bojonegoro mengenai pentingnya manajemen posyandu berbasis teknologi sebagai upaya preventif yang dapat menekan angka malnutrition di Kabupaten Bojonegoro. Dengan pelaksanaan kegiatan pengabdian masyarakat ini memberikan peningkatan kapasitas terhadap kader-kader posyandu, ditunjukkan dengan peningkatan signifikan nilai pre-test dan post-test serta respon peserta dalam kegiatan. Dengan hasil ini dapat membantu para kader-kader posyandu dalam memberikan pelayanan kesehatan cepat dan responsif serta data yang bersifat real time.

\section{Saran}

Kegiatan pengabdian masyarakat ini perlu dilakukan secara berkesinambungan dan perlu untuk dikembangkan lebih lanjut dalam melihat keefetivitasan kegiatan dalam menangani permasalahan yang sedang terjadi sehingga diharapkan kedepannya dapat menjadi daerah percontohan penanganan malnutrition berbasis teknologi.

\section{Ucapan Terima Kasih}

Tim pengabdian masyarakat mengucapkan terima kasih atas bantuan pendanaan dari Keputusan Rektor Universitas Airlangga Nomor 523/UN3/2020 tanggal 1 Juli 2020 
Tentang Pelaksanaan Program Pengabdian Kepada Masyarakat Universitas Airlangga Tahun 2020. Tim pengabdian masyarakat juga mengucapkan terima kasih kepada institusi mitra LSM Gemati dan Pemerintah Desa Genjor yang telibat dalam kegiatan pengabdian ini.

\section{DAFTAR PUSTAKA}

Elston, J. W. T., A. J. Moosa, F. Moses, G.Walker, N. Dotta, R. J. Waldman, dan J. Wright. 2016. "Impact of the Ebola Outbreak on Health Systems and Population Health in Sierra Leone". Journal of Public Health 38 (4), 673-678. DOI: 10.1093/pubmed/fdv158

McGovern, Mark E. Aditi Krishna, Victor M Aguayo, and SV Subramanian. 2017. "A Review of The Evidence Linking Child Stunting to Economic Outcomes". International Journal of Epidemiology 46 (4), 1171-1191. DOI: 10.1093/ije/dyx017

Tim Nasional Percepatan Penanggulangan Kemiskinan. 2017. "100 Kabupaten/Kota Prioritas Untuk Intervensi Anak Kerdil". Kementerian Sekretariat Negara. Diakses dari http://www.tnp2k.go.id/images/uploads/downloads/Binder_Volume1.pdf

Unicef. 2017. "Malnutritions". Unicef Indonesia. Retrived from https://www.unicef.org/indonesia/id/media_19966.html

WHO. 2013. "Nutrition". WHO. Retrieved from http://www.who.int/nutrition/healthygrowthproj_stunted_videos/en/ 